\title{
Ultrasonographic Assessment Predicts Adverse Perinatal Outcomes
}

\author{
Mourad Mohey El-Din El-Said ${ }^{1}$, Wessam Magdi Abuelgar ${ }^{1}$, Haitham Abdel Mohsin Sabba ${ }^{1}$, \\ Ahmed Ramy ${ }^{1}$, Sahar Ahmed Nour EL Deen ${ }^{2}$, and Radwa Rashidy Ali ${ }^{1}$. \\ ${ }^{1}$ Obstetric \& Gynecology Department; Faculty of Medicine, Ain Shams University, Cairo, \\ Egypt. ${ }^{2}$ Pediatric Department; Faculty of Medicine, Ain Shams University, Cairo, Egypt \\ Correspondence:Radwa Rashidy Ali Msc Obstetric \& Gynecology department, Faculty of Medicine, Ain Shams \\ University, Abbasia, Cairo, Egypt..E-mail: doharasheedy@yahoo.com Tel: 02-01283492979
}

\begin{abstract}
Background: pregnancy.

Introduction:

For decades, early pregnancy ultrasound was used only for the assessment of gestational age, detection of fetal viability, diagnosis of twins and the determination of their chorionicity. ${ }^{(1)}$

Recently, ultrasound screening in first trimester of pregnancy provides the most effective way of chromosomal abnormalities screening. The ultrasound assessment of nuchal translucency (NT) is used as non-invasive method for fetal abnormalities. ${ }^{(2)}$

The appearance of a thickened NT during 11-14 weeks of gestation is strongly associated with fetal structural defects, genetic syndromes, and poor perinatal outcomes. ${ }^{(3)}$

Increased NT can be caused by different mechanisms, such as disturbance in lymphatic development, altered extracellular matrix, and cardiac failure. ${ }^{(3)}$
\end{abstract}

Objective:The aim of this work was to evaluate accuracy of the ultrasonographic assessment at the first or the second trimester of gestation as a predictor of adverse outcome in high risk pregnancies.

Patients and methods: A cross sectional study was conducted on 85 consecutive high risk pregnancies attending the Antenatal Clinic and Medical Genetics Center of Ain Shams University. Nuchal translucency thickness was obtained for all cases recruited during $1^{\text {st }}$ trimester. Nuchal fold thickness was obtained for all cases recruited during $2^{\text {nd }}$ trimester.We prospectively evaluated the outcome of each

Results:The mean age of participants, mean marriage duration, and gestational age were $32.5 \pm 6$ years, 7.1 \pm 3.3 years and $14.5 \pm 2.1$ weeks respectively.Increased NT thickness and NF thickness were present in $5 \%$, and $8.89 \%$ respectively.Down syndrome was found in $1.2 \%$ of current pregnancy outcome, while, cystic hygroma was found in $1.2 \%$, cystic hygroma with hydrops was found in $1.2 \%$, skeletal dysplasia and renal agenesis was found in $1.2 \%$ missed abortion was found in 3.53\%. There is a highly significant difference between normal outcome pregnancy and abnormal outcome pregnancy regarding mean NF thickness while no significant differences regarding NT thickness.

Conclusion:The findings of our prospective study demonstrate the feasibility of using NF thickness to screen for aneuploidies, adverse perinatal outcome in high risk pregnancies.

Keywords: Nuchal fold thickness, Nuchal translucency, perinatal outcome, high risk pregnancy.

A thickened nuchal fold is considered to be one of the most sensitive and specific of the minor markers for fetal Down syndrome. ${ }^{(4)}$

The 15-20 weeks of pregnancy is the optimum gestational age for nuchal fold measurement when the normal skin thickness tends to be relatively constant. ${ }^{(5)}$

Thickened nuchal fold $\geq 6 \mathrm{~mm}$ was found in $40 \%$ of fetuses with Down syndrome with a positive predictive value of $69 \%$ in the high-risk pregnancies. A thickened nuchal fold is associated with other euploid syndromes, such as Noonan syndrome, and heart defects. ${ }^{(5)}$

\section{Subjects and Methods}

- A cross sectional study was conducted on 85 consecutive high risk pregnancies attending the Antenatal Clinic and Medical Genetics Center of Ain Shams University. 
- The high risk pregnancy included those with advanced maternal age (maternal age above 35 years).those with previous child with chromosomal abnormality, history of parental chromosomal abnormality or history of previous recurrent miscarriages.

- Nuchal translucency thickness was obtained for all cases recruited during $1^{\text {st }}$ trimester. It was measured in the sagittal plane as the maximum thickness of the sonolucent zone between the fetal skin and the soft tissue overlying the cervical spine or the occipital bone. ${ }^{(\boldsymbol{b})}$ Nuchal translucency thickness $>2.5 \mathrm{~mm}$ was considered abnormal. ${ }^{(7,8)}$

- Nuchal fold thickness was obtained for all cases recruited during $2^{\text {nd }}$ trimester. It was measured from a transverse view of the fetal head that including the cerebellum, occipital bone and cavum septi pellucidi, slightly below the biparietal diameter. The calipers were placed from the outer edge of the occipital bone to the outer edge of the skin. ${ }^{(9)}$ Nuchal fold thickness $\geq 6 \mathrm{~mm}$ was considered abnormal. ${ }^{(5)}$

The outcome of these pregnancies was assessed. The adverse pregnancy outcomes included termination of pregnancy for fetal malformations or intrauterine death, miscarriage and intrauterine growth restriction.

\section{Ethical considerations}

Informed consent was taken from every pregnant participating in this study. The study methodology was reviewed and approved by the Research Review Board of the Obstetric and Gynecology Department, Faculty of Medicine, Ain Shams University.

\section{Statistical methods:}

Statistical analysis was done on a personal computer using IBM $\odot$ SPSS $\odot$ Statistics version 21 (IBM@) Corp., Armonk, NY, USA) and MedCalc(C) version 12.5 (MedCalc(C) Software bvba, Ostend, Belgium).

Numerical variables were presented as median and interquartile range and between-group differences were compared using the MannWhitney $U$ test. Qualitative variables were presented as number and percentage and intergroup differences were compared using Fisher's exact test.

Receiver-operating characteristic (ROC) curve analysis was used to examine the value of continuous variables for prediction of binary outcomes. For categorical predictors, simple binary logistic regression was first applied to estimate the predicted probabilities of the binary outcomes of interest which were then used to plot the ROC curves. $\mathrm{P}<0.05$ is considered statistically significant.

\section{Results:}

The mean age of participant was $32.5 \pm 6$ years with mean gestational age of $14.5 \pm 2.1$ weeks (table 1). Only $2.4 \%$ of the participants were smokers. 5 patients $(5.9 \%)$ of the participants were diabetics, 2 patients $(2.4 \%)$ were hypertensive, and 1 patient (1.2\%) was hypothyroid.

Studying the history of previous miscarriages showed that single miscarriage occurred in 8 patients $(9.4 \%)$ and 27 of the participants $(31.7 \%)$ had repeated miscarriages.

The outcome of previous pregnancies was shown in table 2.

Exploring other risk factors for congenital anomalies revealed that consanguinity was present in $17.6 \%$ of the participants. Family history of Down syndrome was present in $9.4 \%$ of cases, Family history of other congenital anomalies was present in $5.9 \%$ of cases, and Parents chromosomal aberrations was relevant in $3.5 \%$ of the participants (table 3 ).

Forty $(47.05 \%)$ participants were recruited in the $1^{\text {st }}$ trimester and $45(52.95 \%)$ participants were recruited in the $2^{\text {nd }}$ trimester.

Increased NT was found in 5\% of participants recruited in the $1^{\text {st }}$ trimester and increased NF was found in $8.9 \%$ of participants recruited in the $2^{\text {nd }}$ trimester (table 4 ).

Increased NT thickness was observed in only 2 cases in the current study only one had poor outcome $(50 \%)$.

Increased NF thickness was found in 4 cases with adverse outcome (80\%). yet, none of the cases with normal outcome had increased NF thickness $(\mathrm{p}<0.001)$.

The outcome of the current pregnancy in the studied sample was $78(91.8 \%)$ pregnancies ended with healthy alive newborn, $3(3.5 \%)$ had missed abortion, 3 (3.5\%) showed congenital anomalies, $1(1.2 \%)$ had Down syndrome (table $5)$.

The median NT in cases with poor outcome was $2.3 \mathrm{~mm}$ compared to $1.5 \mathrm{~mm}$ in normal fetuses 
$(\mathrm{p}=0.09)$. Moreover, the median NF thickness was $3.9 \mathrm{~mm}$ in cases with normal outcome compared to $6.6 \mathrm{~mm}$ in cases with adverse perinatal outcome (table 6).

Figure 1 showed that: the increased NT thickness had an area under the curve of 0.86 (95\% CI; 0.708 to $0.946, \mathrm{p}=0.005$ ), is $100 \%$ sensitive, $71.4 \%$ specific for predicting abnormal pregnancy outcome.

Figure 2 showed that: the increased NF thickness had an area under the curve of 0.98 (95\% CI; 0.886 to $1.000, \mathrm{p}<0.0001$ ), is $100 \%$ sensitive, $90 \%$ specific for predicting abnormal pregnancy outcome.

Table (1): Baseline characteristics of the participants:

\begin{tabular}{llllllll}
\hline Variable & N & Min & Max & Median & IQR & Mean & SD \\
\hline Age (yr) & 85 & 22 & 42 & 33 & $30-36.3$ & 32.5 & 6.0 \\
Gestational age (wk) & 85 & 12 & 19 & 15 & $13-16$ & 14.5 & 2.1 \\
\hline
\end{tabular}

Table (2): Outcome of previous pregnancies

\begin{tabular}{|c|c|c|c|}
\hline Order of previous pregnancy & Outcome & Number & Percent \\
\hline \multirow[t]{7}{*}{ 1st pregnancy } & Living \& well & 43 & 51.8 \\
\hline & Down syndrome \& living & 10 & 12.0 \\
\hline & Down syndrome \& died & 24 & 28.9 \\
\hline & Congenital malformation \& died & 2 & 2.4 \\
\hline & Chromosomal aberration \& died & 1 & 1.2 \\
\hline & Stillbirth & 1 & 1.2 \\
\hline & Infant death & 2 & 2.4 \\
\hline \multirow[t]{7}{*}{ 2nd pregnancy } & Living \& well & 29 & 50.9 \\
\hline & Down syndrome \& living & 10 & 17.5 \\
\hline & Down syndrome \& died & 9 & 15.8 \\
\hline & Congenital malformation \& died & 6 & 10.5 \\
\hline & Chromosomal aberration \& died & 1 & 1.8 \\
\hline & Stillbirth & 1 & 1.8 \\
\hline & Infant death & 1 & 1.8 \\
\hline \multirow[t]{6}{*}{ 3rd pregnancy } & Living \& well & 9 & 31.0 \\
\hline & Down's syndrome \& living & 5 & 17.2 \\
\hline & Down's syndrome \& died & 6 & 20.7 \\
\hline & Congenital malformation $\&$ died & 1 & 3.4 \\
\hline & Stillbirth & 5 & 17.2 \\
\hline & Infant death & 3 & 10.3 \\
\hline \multirow[t]{6}{*}{ 4th pregnancy } & Living \& well & 2 & 15.4 \\
\hline & Down's syndrome \& living & 2 & 15.4 \\
\hline & Down's syndrome \& died & 2 & 15.4 \\
\hline & Congenital malformation $\&$ died & 3 & 23.1 \\
\hline & Stillbirth & 2 & 15.4 \\
\hline & Infant death & 2 & 15.4 \\
\hline 5th pregnancy & Down's syndrome \& died & 4 & 100.0 \\
\hline
\end{tabular}

Table 2 showing the outcome of previous pregnancies of the participants 
Table (3): Risk factors for adverse pregnancy outcome:

\begin{tabular}{|c|c|c|c|}
\hline & & Number & Percent \\
\hline \multirow[t]{2}{*}{ Consanguinity } & Irrelevant & 70 & 82.4 \\
\hline & Relevant & 15 & 17.6 \\
\hline \multirow[t]{2}{*}{ Teratogens } & Irrelevant & 85 & 100.0 \\
\hline & Relevant & 0 & 0.0 \\
\hline \multirow[t]{2}{*}{ Parents' chromosomal aberrations } & Irrelevant & 82 & 96.5 \\
\hline & Relevant & 3 & 3.5 \\
\hline \multirow[t]{2}{*}{ Family history of Down syndrome } & Irrelevant & 77 & 90.6 \\
\hline & Relevant & 8 & 9.4 \\
\hline \multirow[t]{2}{*}{ Family history of fetal malformation } & Irrelevant & 80 & 94.1 \\
\hline & Relevant & 5 & 5.9 \\
\hline
\end{tabular}

Table 3: showing the prevalence of each risk factor for Down syndrome and congenital anomalies among participants. The highest was consanguinity which accounted for $17.6 \%$ of the participants.

Table (4): Qualitative assessment of sonographic indices

\begin{tabular}{llll}
\hline NT thickness & & Number & Percent \\
& Normal & 38 & 95.0 \\
& Abnormal & 2 & 5.0 \\
\hline NF thickness & Normal & 41 & 91.1 \\
& Abnormal & 4 & 8.9 \\
\hline
\end{tabular}

Table (5): Outcome of current pregnancy

\begin{tabular}{llll}
\hline & & Number & Percent \\
\hline Outcome of current pregnancy & Normal & 78 & 91.8 \\
& Missed abortion & 3 & 3.5 \\
& Congenital anomalies & 3 & 3.5 \\
& Down syndrome & 1 & 1.2 \\
\hline
\end{tabular}

Table (6): Comparison of sonographic indices in patients with normal or abnormal outcome of current pregnancy

\begin{tabular}{|c|c|c|c|c|c|c|c|}
\hline \multirow[b]{2}{*}{ Variable } & \multicolumn{3}{|c|}{ Normal outcome } & \multicolumn{4}{|c|}{ Abnormal outcome } \\
\hline & $\mathbf{N}$ & Median & IQR & $\mathbf{N}$ & Median & IQR & p-value \\
\hline NT thickness (mm) & 38 & 1.5 & $1.20-1.80$ & 2 & 2.3 & $1.80-2.80$ & 0.092 \\
\hline NF thickness (mm) & 40 & 3.9 & $3.35-4.40$ & 5 & 6.6 & $5.80-8.50$ & $<0.001$ \\
\hline
\end{tabular}


FIGURE 1.ROC curve for prediction of abnormal outcomes using NT thickness.

The increased NT thickness had an area under the curve of $0.86(95 \%$ CI: 0.708 to $0.946, p=0.005)$ for predicting abnormal pregnancy outcome.

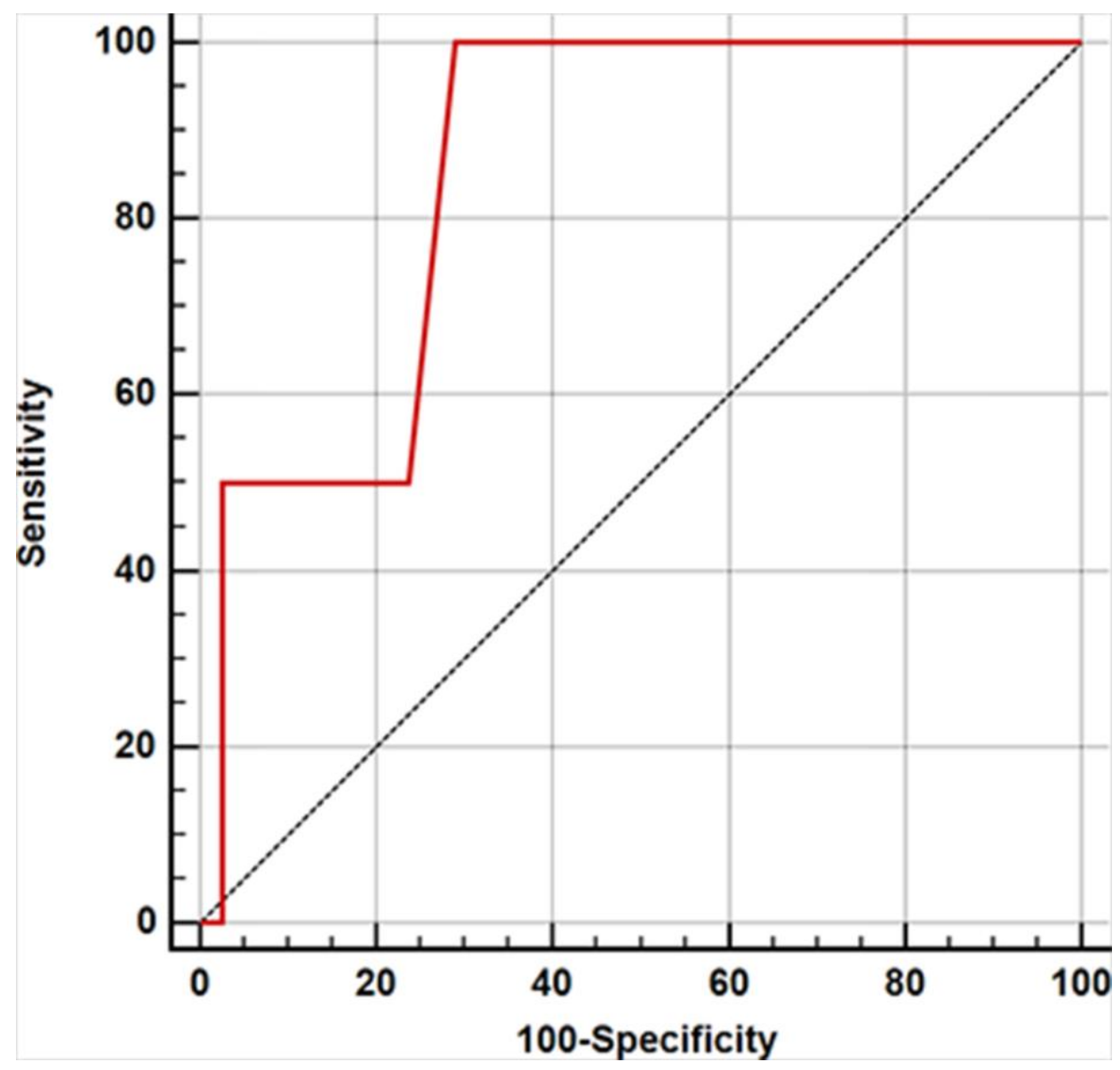


FIGURE 2.ROC curve for prediction of abnormal outcomes using NF thickness.

The increased NF thickness had an area under the curve of 0.98 (95\% CI: 0.886 to $1.000, \mathrm{p}<0.0001)$ for predicting abnormal pregnancy outcome.

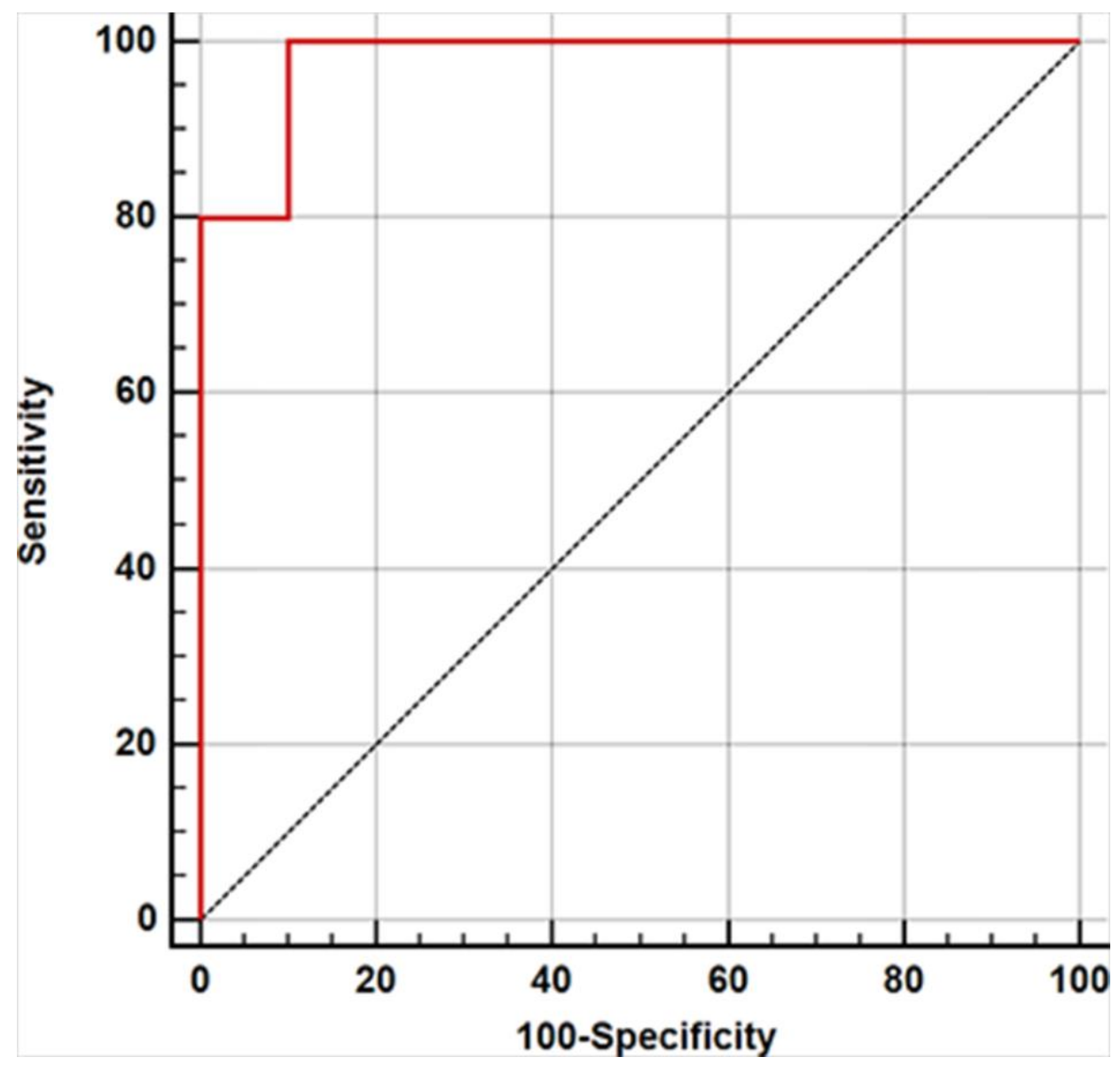




\section{Discussion}

A wide range of screening tests for fetal aneuploidy, in particular trisomy 21 , is now available in both the first and second trimesters. (10)

The aim of this work was to evaluate accuracy of the ultrasonographic assessment at the first or the second trimester of gestation as a predictor of adverse outcome in high risk pregnancies.

We recruited 85 consecutive high risk participants attending the Antenatal Clinic and Medical Genetics Center of Ain Shams University.

The mean age of participant was $32.5 \pm 6$ years with mean gestational age of $14.5 \pm 2.1$ weeks. Forty $(47.05 \%)$ participants were recruited in the $1^{\text {st }}$ trimester and $45(52.95 \%)$ participants were recruited in the $2^{\text {nd }}$ trimester.

The outcome of the current pregnancy in the studied sample was 78 (91.8\%) pregnancies ended with healthy alive newborn, $3(3.5 \%)$ had missed abortion, 3 (3.5\%) showed congenital anomalies, $1(1.2 \%)$ had Down syndrome.

In a study performed by Munoz and colleagues2 cases $(1.4 \%)$ of chromosomal abnormality was detected among 144 pregnancies. $^{(1)}$

In one large cross sectional study 1,183 cases were selected for analysis. From this number 1,170 fetuses were normal $(98.9 \%)$ and 13 fetuses presented with adverse outcome at birth $(1.1 \%)$, including fetal death, (trisomy 21 and 22) in two cases; genetic syndrome (Noonan) in one case; two cases of poly-malformed fetuses; cardiomyopathy in three cases; and other structural defects in five cases. ${ }^{\text {(12) }}$

In the present study, the NF thickness of the only detected fetus with Down syndrome was $6.6 \mathrm{~mm}$.

The mean nuchal translucency was $1.6 \pm 0.4 \mathrm{~mm}$ among participants recruited in 1 st trimester. The nuchal fold thickness was $4.2 \pm 1.4 \mathrm{~mm}$ among participants recruited in 2 nd trimester.

There is little information, if any, regarding NT thickness in Egyptian healthy fetuses. The median NT thickness in the normal fetuses in the current study was $1.5 \mathrm{~mm}$ (range $1.80-2.8 \mathrm{~mm}$ ).

In a study of a total of 2,577 Korean fetuses with a known normal outcome the mean NT thickness was $1.62 \pm 0.50 \mathrm{~mm}$ (range $0.5-5.0 \mathrm{~mm}){ }^{(13)}$

Increased NT thickness was observed in only 2 cases in the current study only one had poor outcome $(50 \%)$.

This non significant relationship was observed due to small sample size with only two cases had NT thickness above $3 \mathrm{~mm}$.

The increased NT thickness had an area under the curve of $0.86(95 \% \mathrm{CI} ; 0.708$ to $0.946, \mathrm{p}=$ 0.005 ), is $100 \%$ sensitive, $71.4 \%$ specific for predicting abnormal pregnancy outcome.

Indeed, different studies using different definitions of increased NT thickness reported that adverse perinatal outcome was associated with increased NT thickness.

In a study of 6650 pregnancies, among the chromosomally normal fetuses with increased NT and no obvious fetal defects, the prevalence of miscarriage or fetal death increased from $1.3 \%$ when NT was between the 95th and 99th percentiles up to20\% for NT over $6.5 \mathrm{~mm} .^{(14)}$

Moreover, the prevalence of fetal abnormalities increased with increased NT: at NT of $3 \mathrm{~mm}$ the anomalies occurred in $2.4 \%$; at NT of $4 \mathrm{~mm}$ the anomalies occurred in $7.1 \%$; at NT of $5 \mathrm{~mm}$ the anomalies occurred in $12.3 \%$; at NT of $6 \mathrm{~mm}$ the anomalies occurred in $16.7 \%$; and at NT of $7 \mathrm{~mm}$ the anomalies occurred in $35.6 \%$. $^{(14)}$

Increased NF thickness was found in 4 cases with adverse outcomes $(80 \%)$. yet, none of the cases with normal outcome had increased NF thickness $(p<0.001)$. The median NF thickness was $3.9 \mathrm{~mm}$ in cases with normal outcome compared to $6.6 \mathrm{~mm}$ in cases with adverse perinatal outcome.

The increased NF thickness had an area under the curve of 0.98 (95\% CI; 0.886 to $1.000, \mathrm{p}<$ 
0.0001 ), is $100 \%$ sensitive, $90 \%$ specific for predicting abnormal pregnancy outcome.

Using NF alone with a commonly used threshold of 5 or $6 \mathrm{~mm}$, reported detection rates for trisomy 21 vary widely, from $4 \%$ to $35 \%$. $^{(9)}$ In the current study, the sensitivity and specificity of different sonographic markers for predicting Down syndrome couldn't be assessed as only one case of Down syndrome was detected.

In conclusion, the findings of our prospective study demonstrate the feasibility of using NF thickness assessment in $2^{\text {nd }}$ trimester to screen for aneuploidies, adverse perinatal outcome in high risk pregnancies.

Our study has some limitations. Importantly, this was a small single site observational study. Further studies with larger sample size are needed.

\section{References}

1. Taipale $\mathrm{P}$, Ammala $\mathrm{M}$, Salonen $\mathrm{R}$ and Hilesmaa V (2003): Learning curve in ultrasonography screening for selected fetal structural anomalies in early pregnancy. Obstet Gynecol., 101 (2): 273-276.

2. Wee LH, Chai HY and Supriyanto E (2011): Computerized nuchal translucency three dimensional reconstructions, visualization and measurement for trisomy 21 prenatal early assessment. International Journal of the Physical Sciences, 6(19):4640-4648.

3. De Mooij YM, Haak MC, Bartelings MM , Twisk JW, Gittenberger-de Groot A , van Vugt JM And Bekker MN (2010): Abnormal ductus venosus flow in first-trimester fetuses with increased nuchal translucency: relationship with the type of cardiac defect. J Ultrasound Med., 29(7):1051-1058.

4. Untersceider J and Malone FD (2011): First and second trimester sonographic screening for fetal Down syndrome. Fetal and Maternal Medicine Review, 22:1 45-66.

5. Shipp TD and Benacerraf BR. (2002): Second trimester ultrasound screening for chromosomal abnormalities. Prenat Diagn., 22: 296-307.

6. Audibert F, Dommergues M, Benattar C., Taieb J, Thalabard JC, and Frydman R.(2001): Screening for Down syndrome using first-trimester ultrasound and second- trimester maternal serum markers in a lowrisk population: a prospective longitudinal study. Ultrasound Obstet Gynecol., 18: 2631.

7. Hafner E, Schuchter K, Liebhart E, Philipp K. (1998): Results of routine fetal nuchal translucency measurement at 10-13 weeks in 4,233 unselected pregnant women. Prenat Diagn., 18: 29-34.

8. Pandya PP, Goldberg H, Walton B, Riddle A, Shelley S, Snijders RJM, Nicolaides KH. (1995): The implementation of first-trimester scanning at 10-13 weeks' gestation and the measurement of fetal nuchal translucency thickness in two maternity units. Ultrasound Obstet Gynecol., 5:20-25.

9. Geipel A., Willruth A., J. Vieten J., Gembruch U. and Berg C.( 2010): Nuchal fold thickness, nasal bone absence or hypoplasia, ductus venosus reversed flow and tricuspid valve regurgitation in screening for trisomies 21,18 and 13 in the early second trimester. Ultrasound Obstet Gynecol., 35: 535-539.

10. Wald NJ, Rodeck C, Hackshaw AK, Walters J, Chitty L, and Mackinson AM (2003): First and second trimester antenatal screening for Down's syndrome the results of the serum, urine and ultrasound screening study. J Med screen., 10:56-104.

11. Munoz H, Puga M, Valdes E, Matamala P, Sepulveda E, Parra M (2003): Association of increased nuchal translucency and ductus venosous assessment between 11 to 14 weeks of gestation. Ultrasound in Obstetrics \& Gynecology, 22(s1):78-81.

12. Gollo CA, Murta CG, Bussamra LC, Santana RM, and Moron AF (2008): Predictive value for fetal outcome of Doppler velocimetry of the ductus venosus between the 11th and the 14th gestation week. Rev Bras Ginecol Obstet., 30(1):5-11.

13. Chung JH, Yang JH, Song MJ, Cho JY,Lee YH, Park SY, Moon MJ, Lim HJ, et al., (2004): The Distribution of Fetal Nuchal Translucency Thickness in Normal Korean Fetuses. J Korean Med Sci., 19: 32-36.

14. Souka AP, Snidjers RJM, Novakov A, Soares W, Nicolaides KH (1998): Defects and syndromes in chromosomally normal fetuses with increased nuchal translucency at 10-14 weeks of gestation. Ultrasound Obstet Gynecol., 11:391-400. 